\title{
Syngenta Professional Products Focuses Chemical Technology on New Applications to Enhance the Quality of Life
}

\author{
Kris Sirchio and Austen Sutton*
}

\begin{abstract}
Professional Products is an innovative and leading business sector of Syngenta comprising focus areas - Seed Care, Home Care and Lawn and Garden. It develops and markets specialty and branded professional products in the seed treatment, home care including public health, turf management, floriculture and amenity sectors. Many countries have a reliable access to food - the production of which is our core competence - and now their populations demand an enhanced experience of their homes, local environment, leisure pursuits and aesthetic aspirations. Syngenta Professional Products provides products and services to businesses that address these markets. Technology originally developed to support agricultural production is refined, improved and integrated into new packages with beneficial applications in urban environments. New, branded products growing out of Syngenta's core competence in chemical innovation help our professional customers serve these new markets to fulfill people's lifestyle aspirations.
\end{abstract}

Keywords: Garden · Home Care · Pest Control · Public Health · Seed Care · Turf Management · Vector Control

\section{Product Portfolio Positioned for Delivering Benefits}

Professional Products is an innovative and key business unit of Syngenta comprising three business units - Seed Care, Home Care and Lawn and Garden. It develops and markets specialty and branded products that address mainly the seed care, home care, and the turf management, floriculture and amenity markets. These markets, already strong in the developed economies, are starting to show good growth in emerging economies where consumers are seeking an enhanced quality of life, and increasingly have the income to pay for it. These include people in the growing economies of the Far East who aspire to similar lifestyles as in the established economies of Western Europe

${ }^{\star}$ Correspondence:

A. Sutton, Global Business Support Manager K. Sirchio, Global Head Professional Products Professional Products

Syngenta Crop Protection AG

R1004 6.40

Schwarzwaldallee 215

$\mathrm{CH}-4002$ Basel

Tel.: +4161323 3028

Fax: +4161323 5608

E-Mail: austen.sutton@syngenta.com and the United States. Their economies are typically in transition from principally agricultural to mixed or urban.

Within the next three years, according to the United Nations Population Database [1], more than half the world's population will for the first time live in an urban environment. Of these estimated 3.47 billion urban dwellers (estimate for 2010), 2.31 billion will live in what the UN describes as the 'less developed regions, excluding the least developed countries'. These are also the regions where urban populations are growing at the greatest rate, and where people's lifestyle expectations are advancing at a startling speed.

For the most part, consumers in these markets have reliable access to high-quality food, the production of which is Syngenta's traditional business. Seed Care technology enables reliable, cost-effective production of food with reduced labor and improved safety. This frees the workforce from drudgery on the land and supports the growth of new consumer markets.

These new consumers are demanding an enhanced experience of their homes, local environment, leisure pursuits, and aesthetic aspirations. They want clean, pest-free homes. They want fuller lives with better leisure opportunities: creating an attractive garden, watching football in a high-quality stadium, or taking part in a game of golf. Like their counterparts in the developed economies, they want to be able to mark special occasions with the gift of cut flowers.

It is this broad aspirational market that Syngenta Professional Products addresses, via its professional partners and distributors. Technology originally developed to support agricultural production is refined, improved and integrated into new packages with a range of beneficial applications for consumers in urbanizing environments. New, branded products growing out of Syngenta's core competence in chemical innovation help our professional customers serve these new markets of consumers eager to realize their lifestyle aspirations and fulfill their desires as well as their needs. The gift of a perfect rose on St Valentine's Day, the use of a pre-treated mosquito net for those people living under the threat of malaria infection, the golf green that plays true, and the weed-free irrigation system for the farmer - these are all ways in which Syngenta Professional Products touch people's lives.

\section{Syngenta Professional Products Organized by Business Activity}

Syngenta Professional Products comprises three areas of activity: Seed Care; Home Care, comprising Professional Pest Management, Vector Control and Materials 
Protection; and Lawn and Garden, comprising Turf, Ornamentals, and Garden. Each business center together with its area of activity is described briefly.

Seed Care is most closely associated with the traditional goal of improving crop yields. This pillar develops highly effective technology to protect the seeds and young plants of agricultural crops against damage by insects and diseases, for better quality and yield, with responsible environmental stewardship. Treated seed is proven to sprout faster, grow more uniformly, and produce more vigorous crops.

Home Care develops pest control products and services that protect public health, homes, built environments, and natural habitats from the threat of pests such as mosquitoes, termites, cockroaches, ants and rodents. This pillar produces chemicals technology that stops the spread of dangerous diseases such as mosquito-borne malaria and dengue fever in Africa.

Lawn and Garden is active in the markets for professional sports turf management, landscape and garden maintenance. It is a leader in turf management solutions for golf and other sports activities. Other professional solutions range from the primarily utilitarian - to control invasive weeds in commercial and industrial sites - to the primarily aesthetic - to assist growers in the capital-intensive and increasingly global business of growing and protecting flowers and ornamental plants to market to consumers.

\section{Innovation in Seed Treatment Responds to Global Social Change and Environmental Needs}

Innovation in chemistry lies at the heart of the Seed Care pillar, which serves farmers and growers - a group whose main concern is the cost-efficient production of food, feed and fiber crops. Seed treatment, a technology in which crop protection ingredients are applied directly onto the seeds before sowing, is one of the most effective and economic ways to protect crops from fungi and insects.

A solution based on a chemical seed applied program often achieves for various diseases and insects better results than treatments applied retrospectively. The grower gets the immediate benefits of an assured start, leading to a better crop yield. Because many seed treatment products are active and effective at the early growth phase of a plant, the grower does not need to apply the same number of chemical treatments after germination. This is more reliable and also, because it can eliminate several additional work-stages, less labor-intensive. This takes out cost and, because treatments are more targeted, minimizes any potential risk during application.

In the more developed economies, producers who use high-cost, genetically modified strains of seed are willing to pay the premium for assured early-season growth and guaranteed return on investment. But the 'plant-and-forget' performance of pretreated seed is also a compelling argument for other reasons. For example, in China many farmers are part-time and the foursix week respite after planting gives them the opportunity to undertake other forms of work. In a rapidly urbanizing world, fewer people are left to work the land, yet the demand for food is still increasing. Pre-treated seed, tailored to the requirements of the local environment and economy, contributes to solving this problem.

An outstanding example of this is the AVICTA ${ }^{\circledR}$ range of products, the first of its kind for systemic nematode (microscopic worm) control, and the first nematicide delivered as a seed treatment. AVICTA moves from the treated seed alongside the growing roots, so protecting the young plant from nematodes attacking the root system. The treatment is pre-delivered - that is, it 'comes in the seed bag'. This promotes faster germination, more vigorous growth, and, ultimately, improved crop quality and yields.
AVICTA Complete Pak (first marketed in the 2006 cotton growing season in US) is a package of nematicide, insecticide, and fungicide all in one. It is a combination of three separately-registered products: AVICTA, a novel seed treatment nematicide, CRUISER ${ }^{\circledR}$ (formula - see Fig. 1), a seed treatment insecticide; and DYNASTY $\mathrm{CST}^{\circledR}$, a seed-delivered fungicide. AVICTA Complete Pak has a favorable environmental and worker safety profile and is compatible with integrated pest management systems. It is an innovative and convenient seed-delivered technology that effectively protects cotton seedlings against all early season pests - nematodes (such as southern root-knot, reniform and lance nematodes), insects (including thrips and aphids), and diseases (such as Fusarium, Pythium, and pre- and post-emergent Rhizoctonia).

Today, most growers still use granular in-furrow insecticides metered out through hopper boxes attached to their planting equipment. This requires frequent refilling, cumbersome product calibration and the need to constantly monitor the product as it flows through drop tubes, which can become clogged during operation. On-theseed protection eliminates these problems. There is no need for measuring out and no guesswork about when to apply treatments.

When using seed treated with AVICTA Complete Pak, field workers' exposure to the active ingredient is limited to handling the seed from the bag. The US Environmental Protection Agency (EPA) has granted AVICTA cotton seed treatment Reduced Risk status when compared to the in-furrow use of aldicarb - the traditional, labor-intensive method of early-season seed protection. The only Personal Protective Equipment (PPE) requirements for proper handling are long-sleeved shirt and long trousers, chemical-resistant gloves, and shoes worn with socks. AVICTA Complete Pak is a new, practical and labor-saving method for cotton growers to protect their crop. Work in the cotton fields has become a)<smiles>CN1COCN(Cc2cnc(Cl)s2)/C1=N/[N+](=O)[O-]</smiles>

$\mathrm{C}_{8} \mathrm{H}_{10} \mathrm{CIN}_{5} \mathrm{O}_{3} \mathrm{~S}$ b)<smiles>CC1(C)[C@@H](C(=O)O[C@@H](C#N)c2cccc(Oc3ccccc3)c2)[C@@H]1C=C(Cl)C(F)(F)F</smiles>

c)<smiles>CO/C=C(/C(=O)OC)c1ccccc1Oc1cc(Oc2ccccc2C#N)ncn1</smiles>

Fig. 1. Formulae of Syngenta insecticides and fungicides: a) Thiamethoxam, the active ingredient of the insecticide CRUISER; b) Lamba-cyhalothrin, the active ingredient of the insecticide DEMAND; c) Azoxystrobin, the active ingredient of the fungicide HERITAGE 


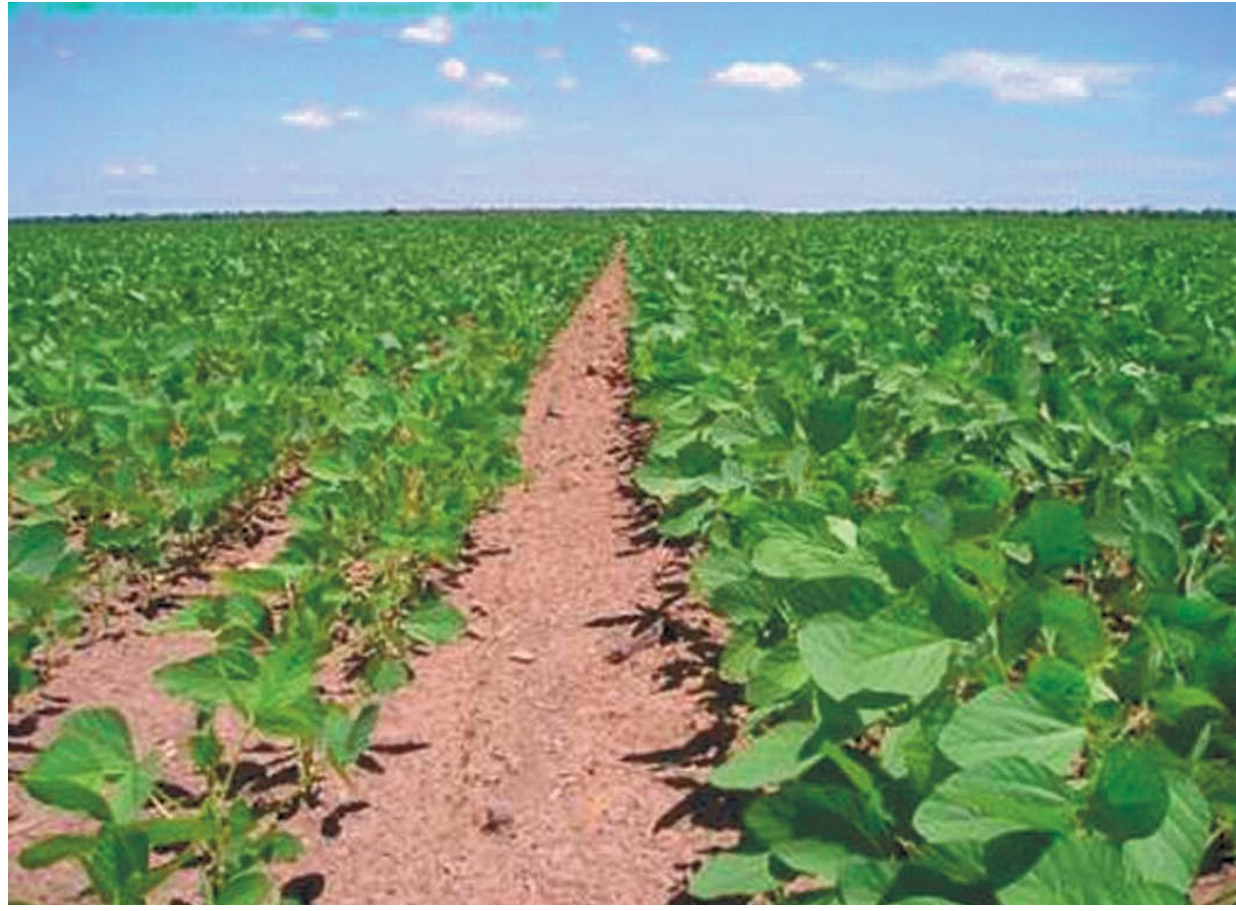

Fig. 2. Comparison of plant growth between seed treated without $(L)$ and with (R) CRUISER

a byword for hard labor, so the removal, at a stroke, of much of the arduous manual fieldwork of cotton production vividly suggests the valuable part chemistry plays in attaining human progress.

Another important product in the Syngenta Seed Care portfolio is CRUISER - an innovative, environmentally safe insecticide seed treatment providing rapid, early-season, broad-spectrum pest control. CRUISER enhances plant vigor, so increasing crop yield-potential (Fig. 2). The active ingredient, thiamethoxam, is available in various formulations specifically developed for seed treatment of corn, cotton, cereals, sugar beet, oilseed rape (canola), rice, and vegetables.

As the plant grows, CRUISER is absorbed and distributed within the plant. Earlyseason pests, which suck and chew on the crop during its most vulnerable phase (the first 30-40 days of growth) are controlled either by feeding on the treated crops, or by coming into contact with the chemical around the seed or plant root system. It acts on different sites in the insect than other chemical products like the organophosphates, carbamates, or pyrethroids, so it also controls pests that have become resistant to those chemical groups.

Treating seeds with CRUISER has been shown to increase crop quality and improve yields by providing exceptional insect control and, vitally, enhancing early-season plant growth. Its impact on non-target organisms such as birds is minimal, because it is only present on the seed surface and inside the plant - in extensive tests it has been seen to be very safe for users and to the environment. CRUISER is now registered in 66 countries on more than 15 crops, bringing the benefits of improved insect control to growers around the globe. It is one of our most important products, with significant sales growth in recent years.

Despite the great promise of this market, growth is not easily achieved. The use of chemistry for any agricultural or environmental application is strictly regulated. There is little margin for error where the safety of humans, animals, beneficial in sects and the environment is concerned. Every innovation must be rigorously tested Seeds with new combinations of active ingredients, as many as five or six, must be proven through germination tests, usually carried out in special growth chambers.

To facilitate and co-ordinate its worldwide research into seed treatment technologies, Syngenta is building a new Seed Care Institute at its Research and Development Center in Stein, Switzerland. Construction started in 2006 and it should be ready by mid-2007. A total investment of around $\$ 7$ million has been made in this center, which should help Syngenta Professional Products shorten the time taken to bring innovations to market.

\section{Chemistry Research at the Heart of Home Care's Portfolio of Peace-of- Mind Brands}

Syngenta's Home Care business develops products that help protect people, homes and properties against insect and fungal pests. Professional Pest Manage- ment delivers pest-control products targeted at structural, nuisance and public-health pests. Vector Control develops chemicals technology to combat the spread of dangerous diseases such as malaria and dengue fever carried by flying insects (known as vectors). Its activities are targeted at the less-developed regions of the world, mainly areas of Africa where malaria is endemic. And a third division, Materials Protection, focuses on solutions for the protection of building products from mold growth.

The Syngenta branding of this portfolio is an assurance to the customer that the product will perform - a key factor when it is hard to determine the product's performance in advance. Syngenta's applied chemicals research, data packages, and experience in the field all combine to reassure the customer - formulator, pest management professional, or end user - that the product works, complies with all applicable regulatory requirements, and is backed by a reputable company. The nearer the product's application is to the customer's home, the more important this effect becomes. When your personal peace of mind is threatened by disease, nuisance or property destruction, you need to be sure that the remedy proposed is convenient, effective, and safe.

\section{Innovative Formulation Keeps Pests under Control for Longer}

The largest market for Professional Pest Management is the United States, where a high per capita income promotes high living standards - often requiring pest eradication in homes, industrial and commercial premises. But elsewhere, urbanization is driving demand- and the world's fastestgrowing urban agglomerations are in Asia. Increasing population densities, combined with rising personal incomes, make people much less willing to share their living space with pests such as mosquitoes, termites, cockroaches, ants, rodents or microbes.

It is estimated that currently $58 \%$ of the world's population lives in the Asia-Pacific area. Of that population, the proportion living in cities will grow from $37.5 \%$ (2001) to $54.1 \%$ by 2030 [1]. And the region's economic growth is running at an average $6.4 \%$, compared with an average $2.8 \%$ in developed economies (3.6\% worldwide) [2]. The region has a warm and humid climate conducive to pests, and several major public health concerns - SARS, avian influenza ('bird flu'), and dengue - have their origins here. These are conditions that will drive demand for effective, safe pest management solutions that confer peace of mind.

DEMAND ${ }^{\circledR} \mathrm{CS}$ is an outstanding example of how Syngenta Professional Products utilizes advanced chemistry technologies 
to anticipate this growing need (formula - Fig. 1). DEMAND CS achieves outstanding results ('knockdown' and 'kill' of insect pests) at low use rates, with great economy, safety and convenience. It is based on iCAPTM, a Syngenta-patented technology where the active ingredient is enclosed in a polymer capsule, which is dispersed in a liquid suspension.

The formulation process for surrounding liquid droplets of an active ingredient with a protective coating is known as micro encapsulation, and was originally developed by Syngenta chemists to encapsulate insecticides in polymers. An encapsulated product works longer, because the active substance is protected inside the capsule. Once applied, it deposits millions of microscopic capsules on the surface for contact by crawling and flying pests - unlike classical emulsion formulations, which tend to have less residual efficacy because the active ingredient is absorbed into porous materials.

Close up, surfaces of commonly treated substrates such as painted and unpainted wood, masonry, concrete, and even vinyl are surprisingly fissured. Particles of less than about five microns can hide in these fissures, where insects do not pick them up. Micro encapsulation controls the size of active ingredient capsules and significantly improves the consistency of their distribution over the surface to be treated - which dramatically increases the efficacy of the treatment.

Once applied, microcapsules work in several ways to control insects and other pests. The microcapsules are readily picked up by insects that contact treated surfaces. Transfer of the toxic dose may occur via direct contact or ingestion. Once attached to the waxy insect cuticle, the lipophilic polymer capsules degrade and the active ingredient is absorbed into the insect. Some pests may ingest the capsules when feeding or preening. It is estimated that one capsule is enough to kill an ant, fly or mosquito, while just five capsules will kill a German Cockroach.

The benefits of this innovative chemistry are several. Microcapsules protect the active ingredient, ensuring the product remains effective on the surfaces where it's needed, even with exposure to outdoor conditions. This means that DEMAND CS is economical in use, minimizing the amount of lamda-cyhalothrin exposed to the environment, yet effective for months even at extremely low use rates. It controls over 25 pest species, including seasonal nuisance pests. And, from the applicator's point of view, iCAP technology means easy and safe mixing and application.

Freedom from life-threatening and debilitating disease is one of the fundamental pre-requisites for an acceptable quality of life. Syngenta's Vector Control team develops insect control solutions designed to reduce the potential for disease transmission, and consists of $\mathrm{ICON}^{\circledR}$ and ACTELLIC ${ }^{\circledR}$ branded products.

Numerous mosquito species are responsible for the transmission of human diseases such as malaria, dengue fever, and West Nile virus. These diseases have their greatest impact in developing countries. Up to $90 \%$ of all reported malaria cases are in sub-Saharan Africa, most seriously affecting pregnant women and children under the age of five. An estimated 3000 African children die every day as a result of malaria. According to recent World Health Organization (WHO) figures, this mosquito-transmitted disease kills over one million people a year and causes an estimated 300 to 500 million acute cases per year [3]. This battle is not yet won. Indeed, the global incidence of vector-borne disease is increasing.

Effective control of malaria and dengue can significantly reduce economic disparity as well as human suffering. Morbidity as a result of infection can seriously hamper a person's ability to work. Economists believe malaria is responsible for a 'growth penalty' of up to $1.3 \%$ per year in some African countries. When compounded over time, this penalty severely cuts the GDP of countries affected by malaria and holds back growth throughout the region, according to the WHO [4]. Controlling malaria has a very significant effect on the overall standard of living in predominantly rural economies where most economic production is generated by agriculture and other manual work.
Syngenta's contribution to the fight against malaria is the ICON product range, comprising the ICON, ICONET, and ACTELLIC products. ICON is based on the high-performance insecticide lambdacyhalothrin, a pyrethroid that is highly effective at low doses against many insects that vector human diseases. ACTELLIC is based on pirimiphos-methyl, an insecticide that is complementary to ICON for resistance management. These products are effective against many other disease-carrying insects as well as all mosquitoes that transmit malaria and dengue.

The use of these products via various application techniques can reduce vector populations where they live, breed, rest or feed, and help interrupt the transmission of diseases between infected and un-infected people. In one example, a Sri Lankan town where nine in ten households were treated with ICON saw the number of cases of malaria drop from 91,000 to 8000 in two years.

As a global provider of insecticides, Syngenta collaborates closely with a variety of partners, including health organizations, humanitarian aid agencies, and academic institutions, to develop and distribute mosquito control products to affected areas and provide education in their safe and effective use. The suppression of debilitating and dangerous disease frees people to develop more productive and prosperous lives. Even in areas that are not subject to malaria, the ICON product range is used to control nuisance insects, such as cockroaches, ants, fleas, ticks and flies.

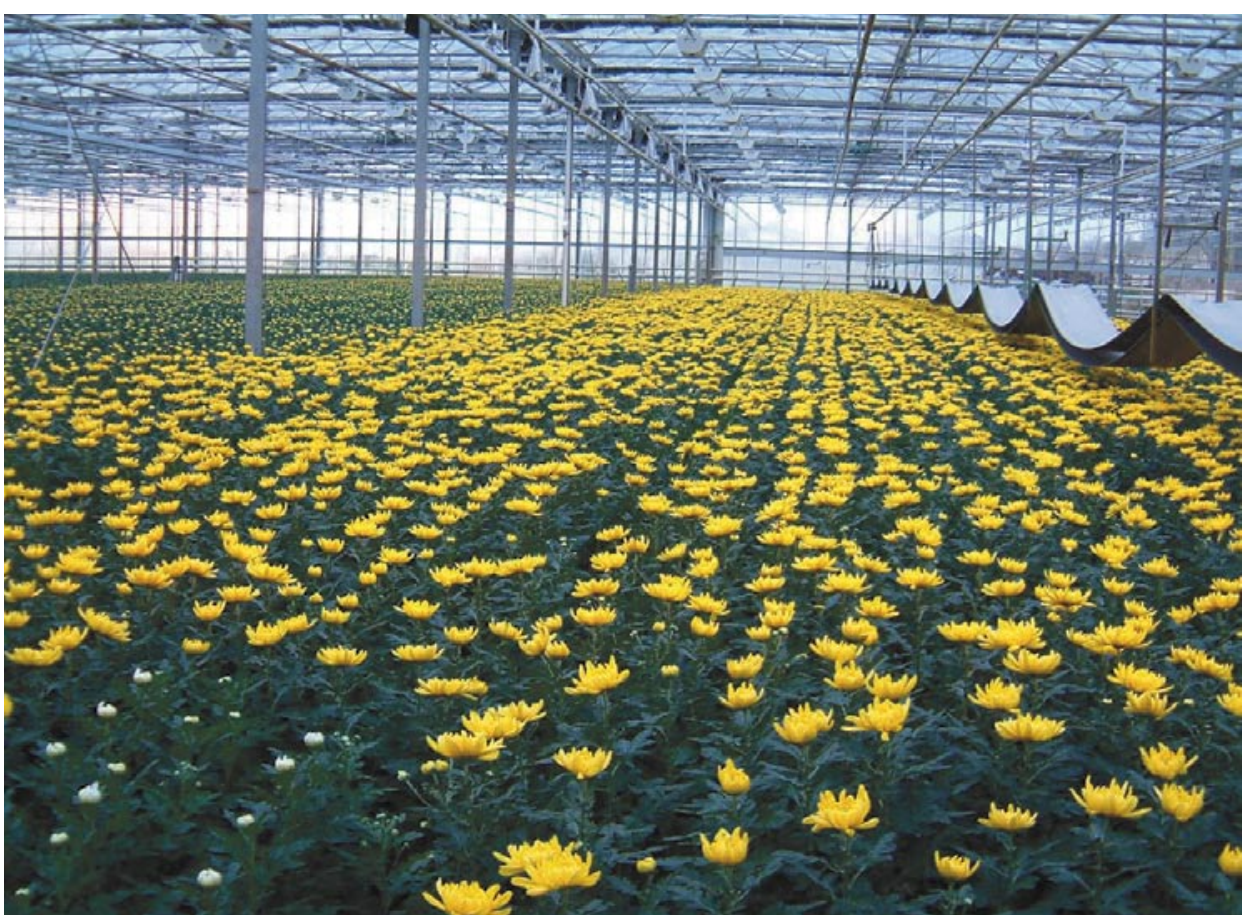

Fig. 3. Greenhouse for cut flowers 


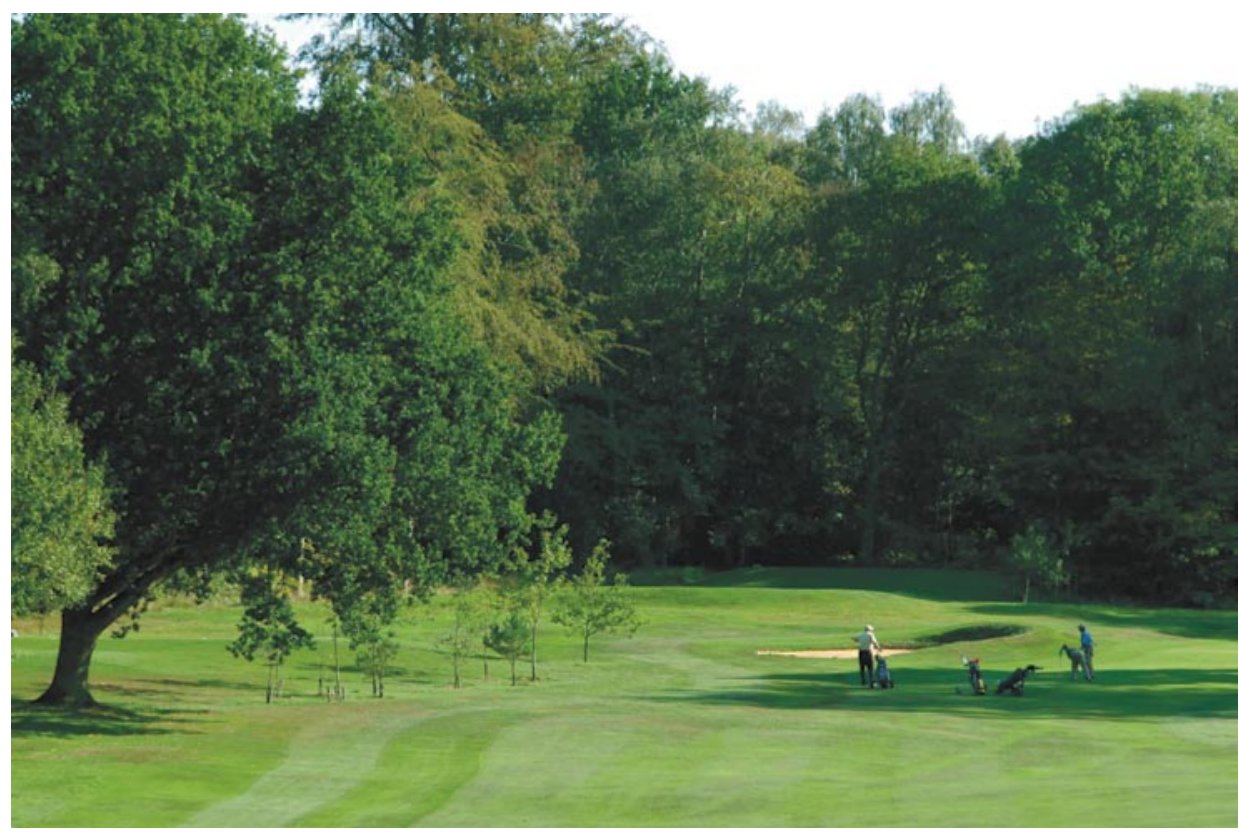

Fig. 4. Golf course

\section{Innovative Chemical Technologies for Human Leisure Activities}

The Lawn and Garden business focuses on markets for professional golf and sports turf management, landscape and amenity maintenance (such as parks, cemeteries, and highways); floriculture, covering flowers and plants grown by professional growers (Fig. 3); and branded products for amateurs to use in their own gardens. Product applications range from the purely utilitarian (for example, weed control in commercial and industrial sites); via the hobbyist (the amateur gardener's campaign to halt slug attack in the garden); to the aesthetic (the commercial grower's production of blooms for gifts and celebrations such as weddings).

The business of Turf Care is turfgrass - the living surfaces of lawns, parks, school grounds, sports fields, golf courses (Fig. 4) and other green spaces, and probably the plant humans most often touch. As spectators and participants, people enjoy turfgrass for recreation and leisure. They prize it for its aesthetic value in setting off the urban landscape. They also benefit directly from its environmental value: a garden lawn releases health-giving oxygen, absorbs harmful carbon dioxide and other air pollutants, and absorbs noise pollution. As a monoculture occurring rarely in nature, turfgrass is emblematic of humans' aspiration to shape the environment to their own aesthetic and recreational ends.

Turfgrass is as susceptible as field crops to insect, weed and disease pests. Globally, Syngenta offers a portfolio of products targeted specifically at turfgrass. These products utilize advanced chemistry to enhance the beauty and health of green spaces by eliminating insects, disease, and weeds. We look here at two examples, a fungicide and a turf growth regulator. Used together, they can take care of most of the maintenance needs of any of the world's estimated 30,000 golf courses (18-hole equivalents) [5].

The fungicide HERITAGE ${ }^{\circledR}$ contains an active ingredient, azoxystrobin, based on the chemical structure of naturally occurring fungicides (formula - Fig. 1). The novel mode of action of HERITAGE prevents fungi from generating energy in the form of adenosine triphosphate (ATP). This is accomplished when azoxystrobin binds to and disables cytochrome b (an important molecule in the production of ATP) in the fungal mitochondria. With cytochrome $b$ unable to play its usual role in the production of energy, the fungal cell stops producing ATP and rapidly dies. HERITAGE can be applied at very low rates and offers exceptional length of control (up to 28 days in some cases) to prevent diseases such as Fusarium, brown patch, Pythium, and snow mold. It is one of a range of disease-control fungicides Syngenta offers, among them BANNER MAXX $^{\circledR}$, DACONIL ${ }^{\circledR}$, INSTRATA $^{\circledR}$, and SUBDUE MAXX ${ }^{\circledR}$.

Also, PRIMO MAXX ${ }^{\circledR}$, a turf growth regulator that modifies the plant's physiology and build-up of carbohydrate reserves, protects the grass when growing conditions deteriorate. Vertical plant growth is reduced, with the benefit of reduced clipping mass when mowing. Greater lateral growth enhances the overall density of the sward, which takes on a healthier, dark-green appearance. Below-ground growth of roots is stimulated, resulting in a denser, healthier turf that is more durable and more resistant to extremes of temperature, foot and vehicle traffic, drought and disease. For sportsfield professionals, this means less watering and mowing to produce thick, velvety swards; for players, a truer playing surface; for spectators, an enhanced aesthetic experience.

PRIMO MAXX has won an enviable reputation among golf superintendents for keeping tees, greens and fairways in great shape. It is in widespread use on courses throughout the world's biggest golf-playing nation, the United States. 'Pre-stress management' - a planned sequence of applications - promotes reliable turf growth even under difficult growing conditions. Golf superintendents know they will not damage their turf if they follow the label instructions - a reassurance that certainly makes their life easier. In a poll for a leading US turf magazine, golf superintendents voted it top product of the past 15 years for helping them perform their job better.

Supporting the products in the Turf Care portfolio are highly researched product information and advice services that help professionals complete their work with greater certitude. The entire product range enjoys the benefits of continuous improvement to formulation chemistry, and this has been key to achieving leadership in turf pesticides. Fast-dissolving formulations, marketed under the brand suffix MAXX, have mostly displaced wettable powders (WP) and emulsifiable concentrates (EC) from the range. Our formulation chemists have overcome many challenges of turning key active ingredients into usable, marketable products that our customers value and generating the return required to re-invest in new formulations.

The Ornamentals business covers an immense range of different plants from geraniums to cacti, and has an estimated market value at the retail or consumer level of $\$ 95$ billion.

Ornamental plants bring color and fragrance into people's lives. Flowers and plants mark and celebrate big occasions in people's lives. From roses for an anniversary to poinsettias at Christmas, flowers vividly symbolize love, gratitude, celebration or condolence.

It is a business that has been transformed by global demand and technology solutions. Cut flowers delivered yearround to florists, supermarkets and garden centers in Europe and the United States are likely to have been shipped by chilled container from growers in countries such as Colombia, Ecuador, and Kenya, helping generate business for agriculture in these developing economies. Non-stop consumer demand means growers must produce top-quality plants and blooms consistently and repeatedly throughout the year, whatever the season. 
Growers must ward off pest and disease attacks that can destroy the commercial value of their stock during the growing cycle. Pesticides amount to only a small proportion of the grower's overall cost of producing reliable, repeatable blooms and delivering them to the point of sale - while labor costs are 25-30\% and energy costs (greenhouse heating, refrigerated airfreight) up to $40 \%$. But the $2 \%$ spent on pesticides is a critical insurance policy for such a capitalintensive business - the farm-gate sale price for a hectare of roses, for example, amounts to $\$ 1$ million a year.

With so much at stake, growers must make exact choices of pesticide and formulation. Syngenta consults closely with growers worldwide to gather their requirements, feeding this vital field research directly into the development of improved products. For example, growers told us they would like to get rid of the unsightly, chalky deposit on the foliage and blooms left by wettable powder formulations. Our chemists were able to produce a liquid formulation that leaves no deposit and avoids damage to the delicate blooms.

The Garden business is driven by changing human demographics and lifestyle aspirations. Many people in the developed economies who enjoy growing incomes and leisure time are turning to gardening. Typically, amateur gardeners own their own home, and are strongly motivated to improve its financial and amenity value by enhancing the garden and turning it into an extension of their living space. Both the 'Baby Boomer' generation, born between 1946 and 1964 and now retiring, and 'Generation X', their successors born 1961-1981 and now earning high disposable incomes, are driving demand for garden equipment, plants, potting soils, fertilizers, and pesticides.

This growing market values different product characteristics to the professional, notably convenience and ease of use. Products need to be ready to use, and have a low concentration of active ingredients. They must be packaged conveniently and safely, a vital precaution in an environment where children and pets are common. At the same time, they must work well to knock down insects, disease or weeds rapidly. Amateurs like the reassurance of rapid results. Under the market-leading Maag brand, Syngenta has served Swiss gardeners for many years with a wide range of products that meet these needs.

\section{Leveraging Technological Capabilities in Chemistry to Address Multiple Levels of Human Need}

Syngenta Professional Products has focused on three key elements to enhance peoples' standards of living - research and development, innovation and convenience.

By improving products through innovation, Syngenta is able to implement technologies that achieve the primary goal of better, more reliable performance, while significantly improving convenience and reducing the requirement for manual labor.

New, branded products growing out of Syngenta's core competence in chemical innovation help consumers realize their aspirations: to create an attractive garden, watch football in a high-quality stadium, improve their golf handicap, gift flowers to their loved ones on a special occasion.

In conclusion, we see that Syngenta Professional Products leverages its technological capabilities in chemistry to address multiple levels of human need. We are achieving growth through the technical performance and utility of our chemistry products to markets that value health, comfort, convenience, and aesthetic fulfillment in addition. Ours is an enterprise where business, social and environmental performance are all mutually dependent - a living example of the proposition that chemistry makes life easier.

Received: December 29, 2006

[1] Population Division of the Department of Economic and Social Affairs of the United Nations Secretariat, 'World Population Prospects: The 2004 Revision and World Urbanization Prospects: The 2005 Revision', esa.un.org/unup.

[2] World Bank,' Prospects for the Global Economy: Global Growth', 30 May 2006, www.worldbank.org/globaloutlook.

[3] World Health Organization Roll Back Malaria Partnership Secretariat, 'Malaria in Africa', Geneva, 2005, www.rbm.who. int.

[4] World Health Organization Roll Back Malaria Partnership Secretariat, 'Economic costs of malaria', Geneva, 2005, www. rbm.who.int.

[5] Source: Golf Research International 2006 www.golf-research-group.com. 